\title{
Simulated Saccadic Stimuli Suppress ON-Type Direction- Selective Retinal Ganglion Cells via Glycinergic Inhibition
}

\author{
Benjamin Sivyer, ${ }^{1}{ }^{\circledR}$ Alexander Tomlinson, ${ }^{1}$ and ${ }^{\circledR W}$. Rowland Taylor ${ }^{2}$ \\ ${ }^{1}$ Casey Eye Institute, Department of Ophthalmology, Oregon Health and Science University, Portland, Oregon 97239, and ${ }^{2}$ School of Optometry and Helen \\ Wills Neuroscience Institute, University of California, Berkeley, California 94720
}

Two types of mammalian direction-selective ganglion cells (DSGCs), ON and ONOFF, operate over different speed ranges. The directional axes of the ON-DSGCs are thought to align with the axes of the vestibular system and provide sensitivity at rotational velocities that are too slow to activate the semicircular canals. ONOFF-DSGCs respond to faster image velocities. Using natural images that simulate the natural visual inputs to freely moving animals, we show that simulated visual saccades suppress responses in ON-DSGCs but not ONOFF-DSGCs recorded in retinas of domestic rabbits of either gender. Analysis of the synaptic inputs shows that this saccadic suppression results from glycinergic inputs that are specific to ON-DSGCs and are absent in ONOFF-DSGCs. When this glycinergic input is blocked, both cell types respond similarly to visual saccades and display essentially identical speed tuning. The results demonstrate that glycinergic circuits within the retina can produce saccadic suppression of retinal ganglion cell activity. The cell-type-specific targeting of the glycinergic circuits further supports the proposed physiological roles of ON-DSGCs in retinal-image stabilization and of ONOFF-DSGCs in detecting local object motion and signaling optical flow.

Key words: electrophysiology; neural circuits; retina; visual processing

\section{Significance Statement}

In the mammalian retina, $\mathrm{ON}$ direction-selective ganglion cells (DSGCs) respond preferentially to slow image motion, whereas ONOFF-DSGCs respond better to rapid motion. The mechanisms producing this different speed tuning remain unclear. Here we show that simulated visual saccades suppress ON-DSGCs, but not ONOFF-DSGCs. This selective saccadic suppression is because of the selective targeting of glycinergic inhibitory synaptic inputs to ON-DSGCs. The different saccadic suppression in the two cell types points to different physiological roles, consistent with their projections to distinct areas within the brain. ON-DSGCs may be critical for providing the visual feedback signals that contribute to stabilizing the image on the retina, whereas ONOFF-DSGCs may be important for detecting the onset of saccades or for signaling optical flow.

\section{Introduction}

Image motion on the retina can occur when an animal moves (global-motion), or when something in the environment moves (local or object-motion). The self-motion that produces globalimage motion on the retina typically elicits powerful feedback systems that drive muscles in the neck and eyes that counter the

\footnotetext{
Received Dec. 5, 2018; revised March 18, 2019; accepted March 19, 2019

Author contributions: B.S. and W.R.T. designed research; B.S. and A.T. performed research; B.S. and W.R.T. analyzed data; A.T. contributed unpublished reagents/analytic tools; B.S. wrote the first draft of the paper; B.S. and W.R.T. edited the paper; B.S. and W.R.T. wrote the paper.

This work was supported by NIH Grants R01 EY014888, R01 EY022070, T32 EY023211, P30 EY010572, and P30 NS061800; and by unrestricted departmental funding from Research to Prevent Blindness (New York, NY). We thank Marla Feller, Mathew Summers, David Vaney, and our anonymous reviewers for helpful comments on the paper.

The authors declare no competing financial interests.

Correspondence should be addressed to W. Rowland Taylor at wrtaylor@berkeley.edu.

https://doi.org/10.1523/JNEUROSCI.3066-18.2019

Copyright $\odot 2019$ the authors
}

effects of the motion and stabilize the image on the retina (Collewijn, 1977; Simpson, 1984). Motion of objects in the environment are also salient, but produce very different behavioral responses, often directing attention to a location (Lettvin et al., 1959), or eliciting avoidance (Münch et al., 2009; Wallace et al., 2013; Yilmaz and Meister, 2013). Such sensitivity to motion could arise at the earliest stages within the visual stream, within the so-called direction selective ganglion cells (DSGCs) in the retina.

DSGCs respond maximally to movement in a narrow range of "preferred" directions, and little if at all to motion in the opposite, "null" directions (Barlow and Hill, 1963; Barlow et al., 1964; Vaney et al., 2012). Mammalian retinas contain two types of DSGCs (Barlow et al., 1964): ONOFF-DSGCs respond to both positive and negative contrasts, whereas ON-DSGCs respond only to positivecontrast. Direction selectivity in both types is mediated largely by directional GABAergic inhibition (Caldwell et al., 1978; Kittila and Massey, 1997; Taylor et al., 2000), arising from specialized inhibitory interneurons called starburst amacrine cells (SBACs; 
Euler et al., 2002; Fried et al., 2002). The directional signals, arising from individual dendrites of the SBACs, are preserved by selective, spatially asymmetric connections between the SBACs and the DSGCs (Lee and Zhou, 2006; Briggman et al., 2011; Wei et al., 2011).

Although the synaptic mechanisms generating directional responses are similar for both the ON-DSGC and ONOFF-DSGC circuits (Yonehara et al., 2011), the two types have different speed tuning and distinct central projections (Huberman et al., 2009; Kay et al., 2011), consistent with different functional roles. ONDSGCs have larger receptive fields and are tuned to lower speeds than the ONOFF-DSGCs (Oyster et al., 1972; Sivyer et al., 2010). The strong projection of ON-DSGCs to the non-image-forming accessory optic system (Soodak and Simpson, 1988), which underlies the visual drive of the optokinetic reflex (Simpson, 1984), suggests an important role for ON-DSGCs in image stabilization as part of the vestibular ocular reflex. The high sensitivity of ON-DSGCs to slow image velocities will complement the loss of vestibular drive at low acceleration that results from the inertia of the endolymph in the semicircular canals (Angelaki and Cullen, 2008). Indeed, selective lesion of DS circuits produces profound deficits in eye-stabilization (Yoshida et al., 2001; Amthor et al., 2002). ONOFF-DSGCs, on the other hand, respond to higher velocities (Oyster and Barlow, 1967; Wyatt and Daw, 1975; Sivyer et al., 2010), and their axons project primarily to the superior colliculus and the lateral geniculate nucleus (LGN; Semm, 1978). The LGN relays the directional information to the superficial layers of V1 (Cruz-Martín et al., 2014), but the role of ONOFFDSGCs in image-forming pathways remains unclear. Some studies suggest these cells are selective for small moving objects within the visual field (Chiao and Masland, 2003; Olveczky et al., 2003). A recent analysis has proposed that both types of DSGCs may be important for signaling global motion or optical flow, produced by rotational head motion or translational body motion (Sabbah et al., 2017).

Here we show that the difference in speed tuning between the ON-DSGCs and the ONOFF-DSGCs arises by virtue of differences in the inhibitory and excitatory inputs. In particular, a glycinergic input, that is specific to ON-DSGCs, suppresses signals produced by sudden contrast changes and visual saccades. The results are consistent with complementary physiological roles for the two types of DSGCs.

\section{Materials and Methods}

Ethical approval and tissue preparation. Experiments involving animals were done in accordance with the National Institutes of Health guidelines, and all procedures were approved by the Oregon Health and Science University Institutional Animal Care and Use Committee. Pigmented rabbits, 5 weeks or older of either sex were dark adapted overnight and anesthetized with ketamine $(50 \mathrm{mg} / \mathrm{kg})$ and xylazine $(10 \mathrm{mg} /$ $\mathrm{kg}$ ) before being killed with an overdose of sodium pentobarbital. Under dim red illumination, the eyes were quickly enucleated, hemisected, and placed in Ames medium equilibrated with $95 \% \mathrm{O}_{2}$ and $5 \% \mathrm{CO}_{2}, \mathrm{pH} 7.4$, at room temperature. Subsequent to enucleation, all procedures were performed under infrared illumination. The retina and attached pigment epithelium were dissected free from the sclera and placed in a recording chamber under a microscope and perfused with Ames medium maintained at $36^{\circ} \mathrm{C}$. Ganglion cell somas were visualized though a $60 \times$ waterimmersion objective and differential interference contrast optics. DSGCs were selectively targeted by their characteristic somatodendritic morphology (Sivyer et al., 2010; Sivyer and Williams, 2013).

Experimental design and statistical analysis. Following the establishment of an extracellular recording, the $60 \times$ objective was replaced with a $10 \times$ water-immersion objective and DSGCs were identified by their responses to a moving bar projected on the receptive field. Whole-cell current-clamp or voltage-clamp recordings were made with the following internal solutions (in mM): $128 \mathrm{~K}$-gluconate, $6 \mathrm{KCl}, 10 \mathrm{Na}$-HEPES, 5 phosphocreatine- $\mathrm{Na}_{2}, 1$ EGTA, $2 \mathrm{Mg}$-ATP, 1 Na-GTP, and 3 QX-314. For voltage-clamp experiments the $\mathrm{K}$ was replaced with $\mathrm{Cs}$. The $\mathrm{pH}$ was adjusted to 7.3 using the appropriate hydroxide. Synaptic conductances were estimated from current-voltage relations sampled at potentials between -95 and $0 \mathrm{mV}$ in $15 \mathrm{mV}$ increments. The visual stimulus was repeated for each potential. Excitatory and inhibitory contributions to the total light-evoked synaptic input were estimated by fitting the current-voltage relations as described previously (Borg-Graham, 2001; Taylor and Vaney, 2002; van Wyk et al., 2006; Venkataramani and Taylor, 2010). Drugs were diluted in Ames medium to a final concentration of $1 \mu \mathrm{M}$ strychnine, $10 \mu \mathrm{M}$ 6-Imino-3-(4-methoxyphenyl)-1(6H)-pyridazinebutanoic acid hydrobromide (SR 95531), $50 \mu \mathrm{M}$ 1,2,5,6-tetrahydropyridin-4yl)methylphosphinic acid (TPMPA). Because of its high affinity the time required to washout strychnine exceeded the attainable recording duration for whole-cell recordings. However, after allowing at least $60 \mathrm{~min}$ for washout, recovery of glycinergic IPSPs can be observed in retinal preparations, indicating that the drug effect is reversible.

Visual stimuli were produced using custom software based on the PsychoPy routines (Peirce, 2007; RRID:SCR_006571). The stimuli, generated on a Texas Instruments digital light projector (DLP; Lightcrafter 4500 ), were projected onto the photoreceptor layer through a $10 \times$ waterimmersion objective (0.3 NA, Olympus). Only monochromatic light from the green LED was used, with a peak emission wavelength of 520 $\mathrm{nm}$. The DLP intensity was linearized using a calibrated lookup table. DLP intensity was attenuated using neutral density filters to produce an adapting background photon density of $\sim 3.4 \times 10^{5}$ photons $/ \mu \mathrm{m}^{2}$, which was maintained throughout the experiments. The image of the DLP array was magnified to fill the field-of-view of the $10 \times$ objective, producing a projected image of $\sim 2.6 \mathrm{~mm}$ diameter on the retina. Each pixel on the DLP corresponded to $3.2 \mu \mathrm{m}$ on the retina. To convert distance on the retina to degrees of visual angle we used the conversion factor of $166 \mu \mathrm{m} /$ degree measured for the rabbit eye (Hughes and Vaney, 1981).

Two stimuli were used to probe responses to global motion; a checkerboard stimulus, and a natural scene, "imk00955.iml", obtained from the Van Harteren image database (van Hateren and van der Schaaf, 1998). The checkerboard comprised $100 \mu \mathrm{m}$ squares with randomly assigned intensities of $+80 \%$ or $-80 \%$ relative to the mean luminance level (Fig. $1 A$ ). The natural scene was scaled to span the dynamic range of the stimulus monitor. The mean luminance was 52\% lower than the interstimulus background level and the mean contrast (SD) was $28.7 \%$. Saccadic stimuli were simulated by generating image trajectories based on the measurements of eye and head movements that were made in freely moving rabbits (Collewijn, 1977). For saccades the image moved at $90 \%$, which corresponds to a displacement of $250 \mu \mathrm{m} /$ stimulus frame. Thus, the image jumped between frames by less than one-quarter of the receptive field diameter of the ganglion cell. Saccade distance ranged from $4.5^{\circ}$ to $19.7^{\circ}$ with an average of $13.0^{\circ} \pm 6.8^{\circ}$. The average saccade duration was $160 \pm 68 \mathrm{~ms}$.

Statistical comparisons between cell types were made using unpaired two-tailed Student's $t$ tests assuming normally distributed data. Comparison of pharmacological effects used paired $t$ tests. Results were considered significant for $p<0.05$. Custom routines in Igor Pro (Wavemetrics; RRID:SCR_000325) were used for data analysis. Unless otherwise specified, error bars or error-shading represent \pm SEM.

\section{Results}

Saccade-like motion suppresses ON-type DSGCs selectively To compare ON-DSGC and ONOFF-DSGC responses during rapid and slow eye movements we simulated saccades and slow image drift at velocities similar to those encountered during normal behavior (Collewijn, 1977). During simulation of global image motion on the retina that occurs during eye movement, random checkerboard images covered the full stimulus area of $\sim 2.6 \mathrm{~mm}$ diameter. To assess the effect of saccades on the ongoing neural activity, a maintained level of activity in the DSGCs 
A
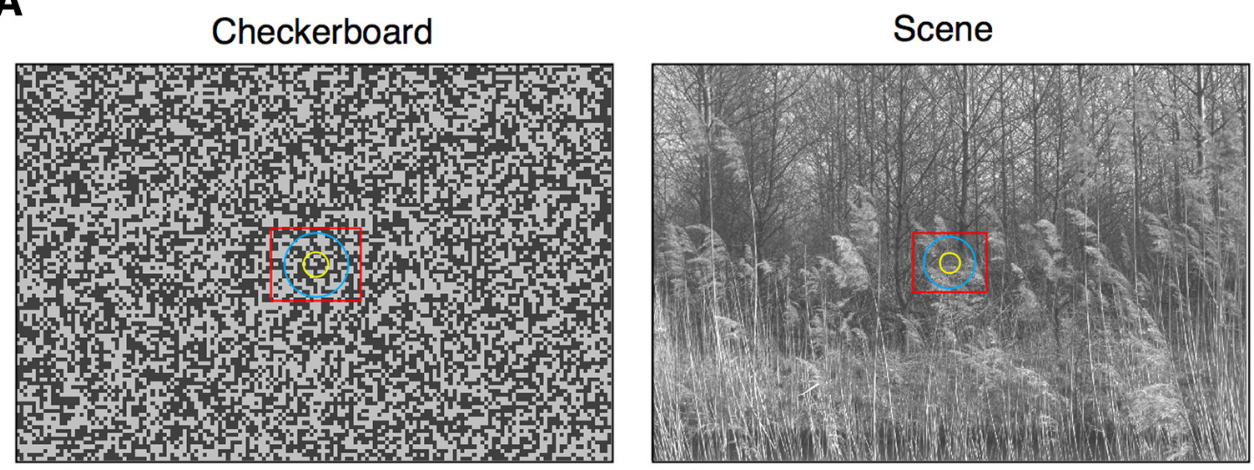

$\overline{2 \mathrm{~mm}}$

$2 \overline{\mathrm{mm}}$

B Checkerboard

ONOFF DSGCS

\section{Appears}

ON DSGCs

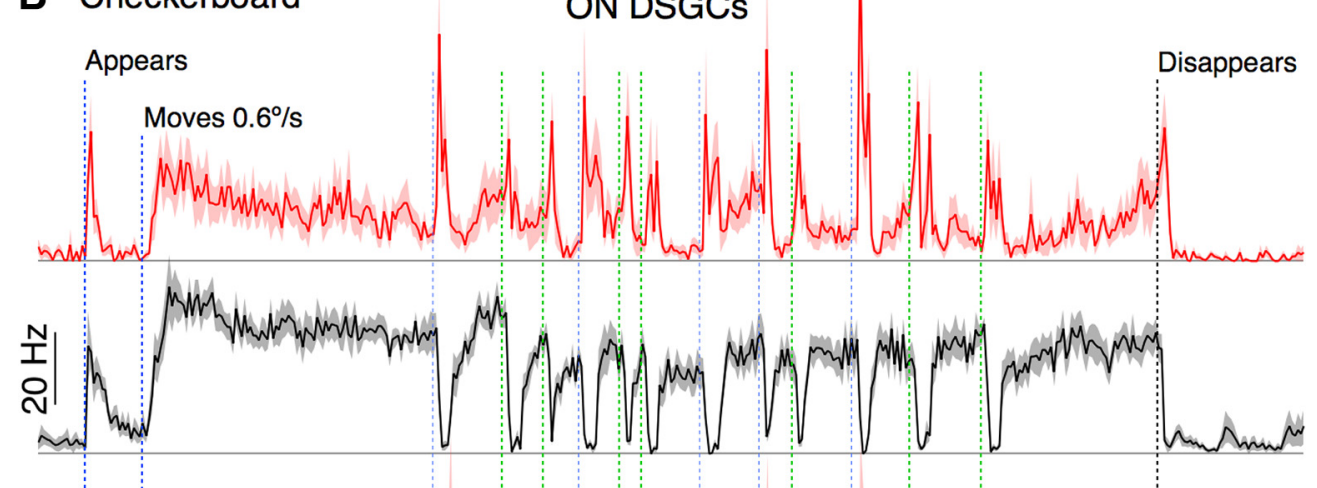

C Scene

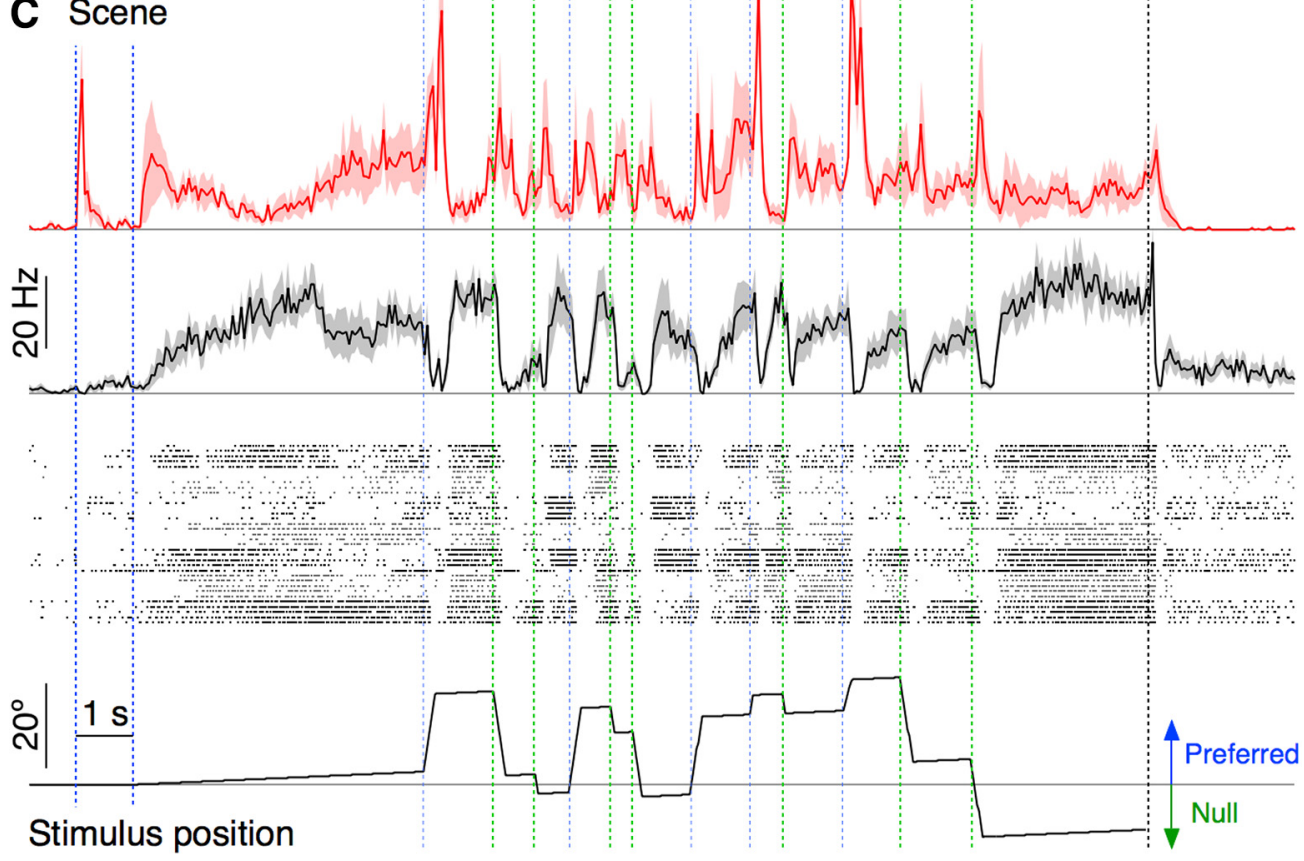

Figure 1. Simulated saccades suppress preferred-direction responses in ON but not ONOFF-DSGCS. A, Images used for simulated saccades. Left, An example checkerboard. Right, the natural scene used. The image sizes were extended outside the projection area to allow for generation of saccades. The red rectangles show the size of the stimulus DLP array, and the blue circles show the area projected onto the retina. The yellow circles show the approximate extent of a typical ON-DSGC dendritic arbor. See Materials and Methods for details on intensities and dimensions. $\boldsymbol{B}$, Average PSTHs from ONOFF- (red, $n=7$ ) and ON- (black, $n=10$ ) DSGCS during stimulation with the drifting checkerboard shown in $A$. Shading shows the SEM. The symbols show the timing and direction of saccades (blue, preferred; green, null). C, Average PSTHs for ONOFF- (red; $n=10$ ) and ON- (black; $n=8)$ DSGCs during stimulation with the drifting natural image shown in $\boldsymbol{A}$. Raster plots for several ON-DSGCS during the natural scene stimulation are shown. Each line of dots shows the timing of the spikes during a single trial. Different cells are shown alternately in gray and black. The trace at the bottom of the figure shows the position of the stimuli along the preferred-null axis as a function of time, i.e., the slope represents the speed. Speed of saccades was $90^{\circ} / \mathrm{s}$. In the intervals between saccades the positive slope indicates the constant drift of the image in the preferred direction $(0.6 \%)$. The same stimulus trajectory was used for natural scenes and checkerboards. The vertical broken lines mark the saccade onsets, with blue and green lines marking the preferred- and null-direction events, respectively. 


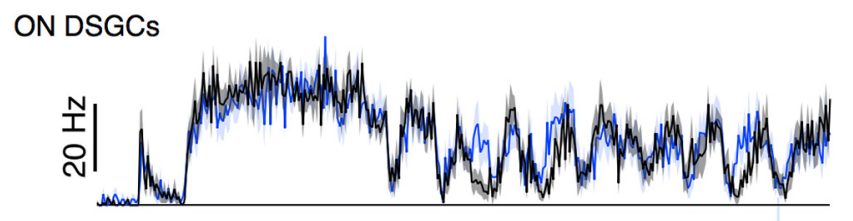

ONOFF DSGCs

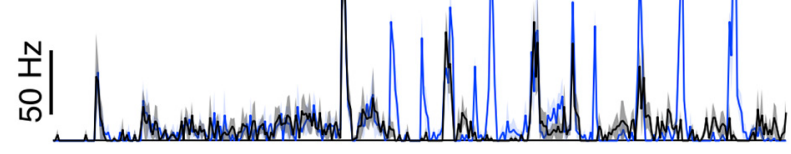

Stimulus velocity

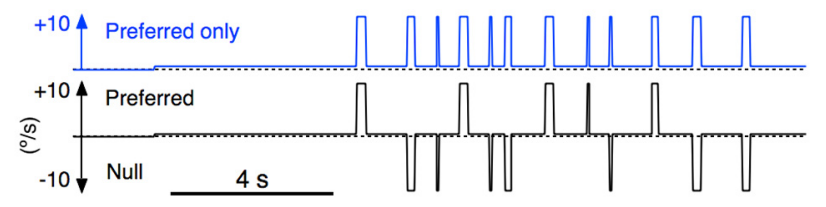

Figure 2. The decrease in directional responses in ONOFF-DSGCs during rapid global motion only occurs at very high stimulus speeds. Averaged spike responses (8 cells) to simulated rapid eye movements in the preferred and null directions at image velocities producing clear directional responses of ONOFF-DSGCs $\left(10^{\circ} / \mathrm{s}\right)$. The checkerboard stimulus and the times at which the rapid motion events occurred was the same as in Figure 1. In one set of trials, stimuli moved only in the preferred direction (blue) and in a second set, stimuli moved in the preferred and null directions (black).

was generated by continuously drifting the stimulus image at $0.6 \%$ in the cell's preferred direction during intervals between saccades. Linear saccades were generated in either the preferred or null direction (Fig. 1, stimulus trace). When the stimulus first appeared, it produced a burst of spikes that subsided to near zero within $\sim 1 \mathrm{~s}$ (Fig. $1 B$ ). The steady drift in the preferred direction $(0.6 \%)$, produced sustained firing in the ON and ONOFFDSGCs. Sustained firing was higher in ON-DSGCs than ONOFFDSGCs (ON-DS, $n=10$; ONOFF-DSGC, $n=7$; unpaired $t$ test, $p=0.0040)$. The simulated saccades strongly suppressed preferreddirection spiking in the ON-DSGCs. Spiking increased regardless of saccade-direction in the ONOFF-DSGCs indicating a loss of directional signaling at these high velocities (Fig. $1 B$ ). On return to the slow drift in the preferred direction at the end of each saccade, spiking in the ON-DSGCs recovered rapidly, indicating that the saccadic suppression is relatively transient.

Random checkerboard images over-represent high spatial frequencies relative to natural images, in which the power declines inversely with spatial frequency (Simoncelli and Olshausen, 2001). To ensure that the responses were pertinent to natural images, we repeated the global motion stimuli with the same velocity trajectories but using a natural scene instead of the checkerboard. We chose an image that a rabbit might conceivably experience, and that had fairly uniform contrast (Fig. 1A; see Materials and Methods). The ON-DSGCs responded to the appearance of the checkerboard, but not to the appearance of the scene (Fig. $1 B, C$, compare black traces), most likely because the scene produced a step decrease in mean luminance which offset the drive produced by the step increase in spatial contrast. Similar to the checkerboards, the identical motion trajectories for the natural scenes suppressed preferred-direction spiking in ON-DSGCs but not ONOFF-DSGCs (Fig. 1C). For the ON-DSGCs the initial slow drift during the conditioning phase elicited a lower average spike rate for the natural scene than for the checkerboards (scene: $17 \pm$ $8.8 \mathrm{~Hz}, n=8$; checkerboard: $30.5 \pm 12.1 \mathrm{~Hz}, n=10, p<0.017$ ).
The two stimuli produced similar sustained firing in the ONOFFDSGCs (scene: $10.7 \pm 8.2, n=5$; checkerboard: $12.7 \pm 9.3, n=$ $7, p=0.69)$.

Similar to the checkerboards, for the natural scenes the ONOFF-DSGCs showed an increase in spiking for both the preferred and null directions, indicating a reduction in the strength of the directional tuning. The average number of spikes produced by the preferred- and null-direction saccades was the same for either the checkerboards or scenes (checkerboards: $n=7, p=$ 0.23 ; scenes: $n=5, p=0.094)$. We wanted to be certain that the lack of saccadic suppression in the ONOFF-DSGCs was not related to this loss in direction-selectivity. Therefore, we compared responses of ON-DSGCs and ONOFF-DSGCs to rapid global motion at lower velocities where the ONOFF-DSGCs remained strongly directional $(10 \%)$. These stimuli strongly suppressed preferred-direction firing in the ON-DSGCs but not in the ONOFF-DSGCs (Fig. 2). Overall, these results demonstrate that rapid motion simulating saccadic eye movements selectively suppresses ON-DSGCs but not ONOFF-DSGCs. This selective suppression is produced by both spatially uncorrelated checkerboard stimuli and by highly correlated natural images.

Because ON-DSGCs and ONOFF-DSGCs both respond during low-speed global image motion but not at high speeds, we sought to quantify how steeply the responses of the two cell types diverged as the stimulus speed increased. We examined the speed tuning functions for both global and local image motion, because ONOFF-DSGCs are known to respond more strongly to local versus global image motion. Global motion refers to stimuli that are elicited for example by self-motion, when the eye or head moves and the image on the entire retina moves coherently. Local motion refers to stimuli that differentially activate the receptive field center, such as an object moving relative to the background. The stimulus paradigm for global motion was similar to that used in Figure 1. Figure $3 A$ shows responses to full-field checkerboard stimuli. The stimulus appeared and remained static for $1 \mathrm{~s} \mathrm{before}$ drifting at $0.6 \% \mathrm{~s}$ in the preferred direction for $4 \mathrm{~s}$ and then abruptly increasing to a test speed for a further $4 \mathrm{~s}$. The initial reference speed produced sustained firing in both types of DSGCs, whereas increasing the speed elicited progressively less spikes in the ON-DSGCs, but more spikes in the ONOFF cells (Fig. $3 A, B$ ). The speed-tuning of the two types of DSGCs for this global motion is shown in Figure $3 C$ (solid squares). The mean firing rate over the $4 \mathrm{~s}$ stimulus interval declined for ON-DSGCs as the speed was increased above the initial drift rate $(0.6 \% \mathrm{~s})$, and was $50 \%$ suppressed at $\sim 1.2 \%$. We measured the maximum firing rate ONOFF-DSGCs, which occurred near the beginning of the $4 \mathrm{~s}$ stimulus interval. Peak firing rate increased steadily without saturation over this velocity range (Fig. $3 C$, solid red).

ONOFF-DSGCs show surround inhibition, which suppresses responses to global motion and hence tunes cells to respond more robustly to small objects that selectively stimulate the receptive field center (Chiao and Masland, 2003; Olveczky et al., 2003; Hoggarth et al., 2015; Im and Fried, 2016). We asked whether the strong suppression of ON-DSGCS during rapid image motion might result from strong wide-field inhibition activated during global motion. To address this question, we used elongated bars to stimulate the center receptive fields of ON- and ONOFFDSGCs without engaging the inhibitory surround. The length of the bar was adjusted so that the leading and trailing edges produced well separated ON and OFF responses in the ONOFFDSGCs (see Materials and Methods). For these local motion stimuli, the peak ON-response increased monotonically as a function of the bar velocity for ONOFF-DSGCs, reaching half- 
maximal responses at $\sim 1.8 \%$ (Fig. $3 B, C$, open red symbols), but declined progressively for the ON-DSGCs (Fig. $3 B, C$, open black symbols). This stimulus also revealed small trailing-edge OFF responses in the ON-DSGCs (Fig. 3B, inset, arrow), as has been reported previously (Ariel and Daw, 1982; Nirenberg and Meister, 1997; Roska and Werblin, 2001; Rentería et al., 2006; Sun et al., 2006; Ackert et al., 2009). In agreement with the previous work, the spike rates for local motion tended to be higher than for global motion (Fig. 3C, compare corresponding red and black symbols; Chiao and Masland, 2003; Olveczky et al., 2003; Hoggarth et al., 2015; Im and Fried, 2016). Overall, these observations are in accord with previous work showing differences in the temporal/velocity tuning of ON- and ONOFFDSGCs (Oyster, 1968; Wyatt and Daw, 1975; Sivyer et al., 2010).

The ONOFF-DSGC firing rate varied widely in response to the constant-velocity global motion stimuli (Fig. $3 A$, red), however, similarities in the structure of the peristimulus spike-time histograms (PSTHs) become evident when the they are normalized in time (Fig. 3D). After this transformation, the peaks and troughs in the PSTHs appeared to be remarkably reproducible, consistent with the idea that the cells respond similarly to the spatial structure of the checkerboard stimulus, regardless of velocity. Such invariance might allow the integrated spike counts in ONOFF-DSGCs to provide a measure of optical flow over a range of image velocities (Sabbah et al., 2017). Overall, the data indicated that the selective suppression of ON-DSGCs versus ONOFF-DSGCs during saccadic stimuli is consistent with a marked difference in velocity tuning over a range of stimulus speeds.

\section{Saccadic motion activates glycinergic inhibition in ON-type DSGCs}

Previous data indicated that differences in velocity tuning in ON-DSGCs versus ONOFF-DSGCs resulted in part from stronger activation of inhibition over excitation in ON-DSGCs at higher temporal frequencies (Sivyer et al., 2010). To further investigate the synaptic basis for such differences we recorded voltage-responses while stimulating cells with a centered spot that was sinusoidally modulated over a range of temporal frequencies. In agreement with our previous analysis (Sivyer et al., 2010), spiking in ON-DSGCs declined dramatically at stimulus frequencies $>1 \mathrm{~Hz}$, whereas the ONOFF-DSGCs continued to respond up to $8.5 \mathrm{~Hz}$, the highest frequency tested (Fig. $4 A$ ). The loss of spiking in the ON-DSGCs was accompanied by the appearance of hyperpolarizing IPSPs that were time-locked to the stimulus frequency (Fig. $4 A, B$ ). In an overlapping ONOFF-DSGC

A

C structure of the stimuli.
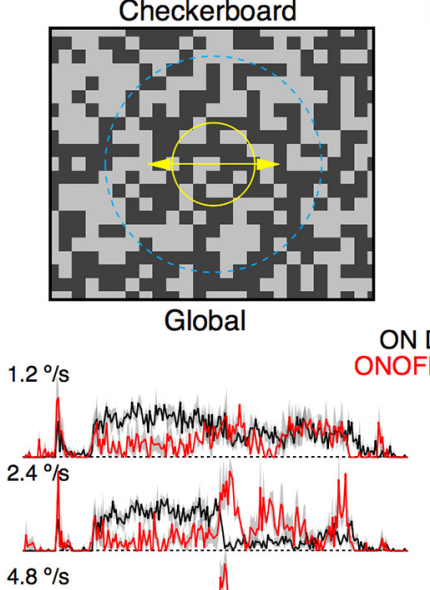

ONOFF DSGCS

B
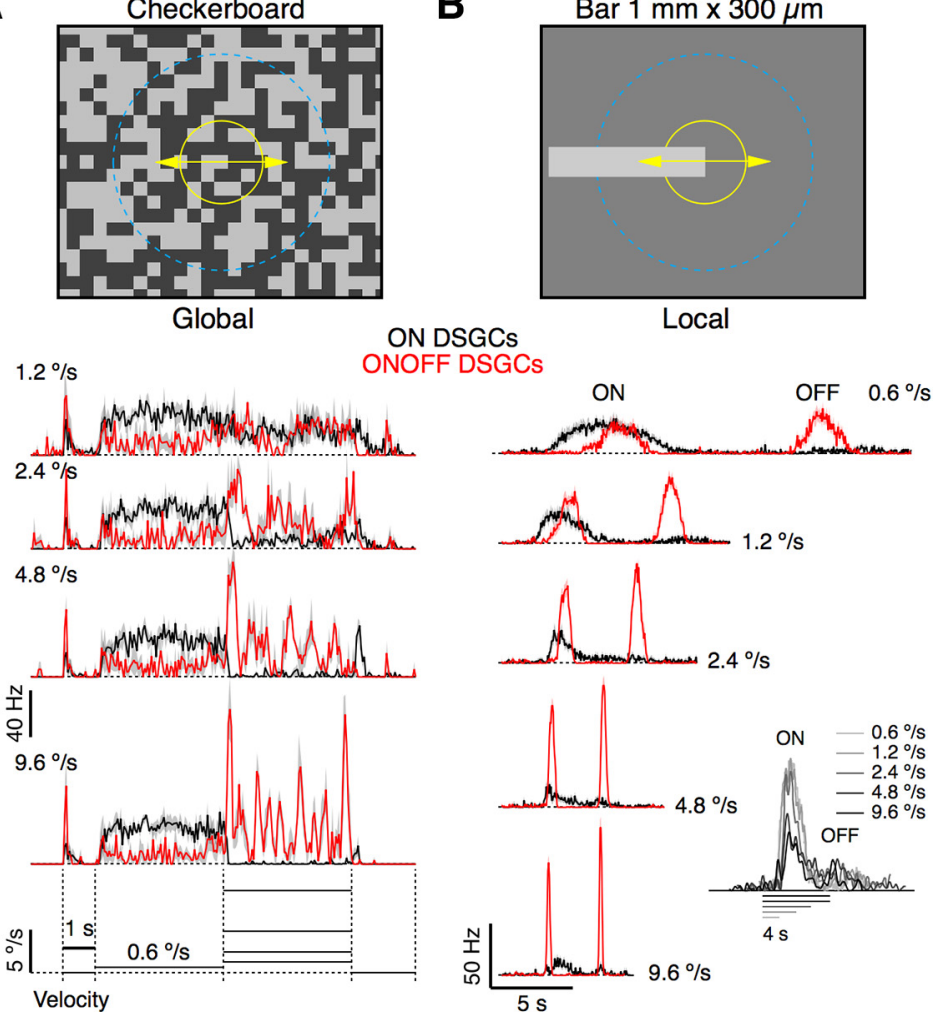

D
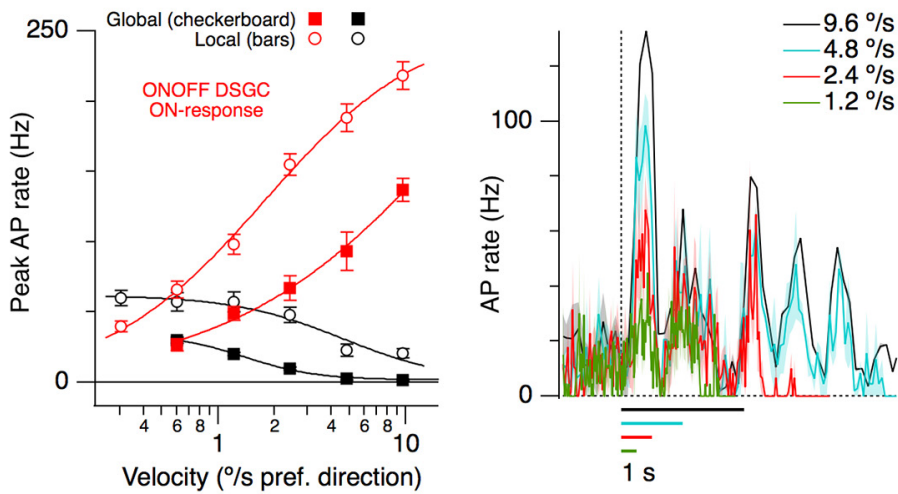

Figure 3. Speed tuning of ON- (black) and ONOFF- (red) DSGCS. A, Average PSTHs recorded for a moving full-field checkerboard stimulus. The stimulus appeared and after a $1 \mathrm{~s}$ delay began drifting in the preferred direction at $0.6 \% \mathrm{~s}$ for $4 \mathrm{~s}$ before abruptly increasing speed. This stimulus timing is shown beneath the traces. ON-DSGCs shown in black $(n=3)$ and ONOFF-DSGCs in red $(n=4)$. B, Average PSTHs recorded for ON- (black; $n=11)$ and ONOFF- (red; $n=12)$ DSGCs in response to a bright bar on a gray background drifted across the receptive field center in the preferred direction at the speeds indicated. The length of the bar was adjusted to separate leading and trailing edge responses. Inset; replot of the PSTHs for the ON-DSGCs with the time axis rescaled so that the responses to the leading and trailing edges of the stimulus were superimposed. The calibration bars beneath the traces all denote $4 \mathrm{~s}$, according to the speed and length of the stimulus bars. C, Speed-dependence of spike responses to global (filled symbols) and local motion (open symbols) for ON-DSGCs (black) and ONOFF-DSGCs (red; on response only). Data drawn from cells in $\boldsymbol{A}$ and $\boldsymbol{B} . \boldsymbol{D}$, Expanded segment of the PSTHs from $\boldsymbol{A}$ normalized in time to show the correspondence of the responses to the spatial recorded simultaneously we saw no evidence for hyperpolarizing IPSPs (Fig. 4A, red). Two other pairs of overlapping ON- and ONOFF-DSGCs recorded simultaneously showed similar results.

The IPSPs were activated during the upswing of the stimulus intensity and were time-locked to the flicker (Fig. 4B), consistent with drive through the ON-pathway. The width at half-height of the IPSPs ranged from $\sim 30 \mathrm{~ms}$ at $8.5 \mathrm{~Hz}$ to $\sim 90 \mathrm{~ms}$ at $1 \mathrm{~Hz}$. We examined the activation-latency by measuring the timing of the peak IPSP, expressed as the phase relative to the start of the stim- 


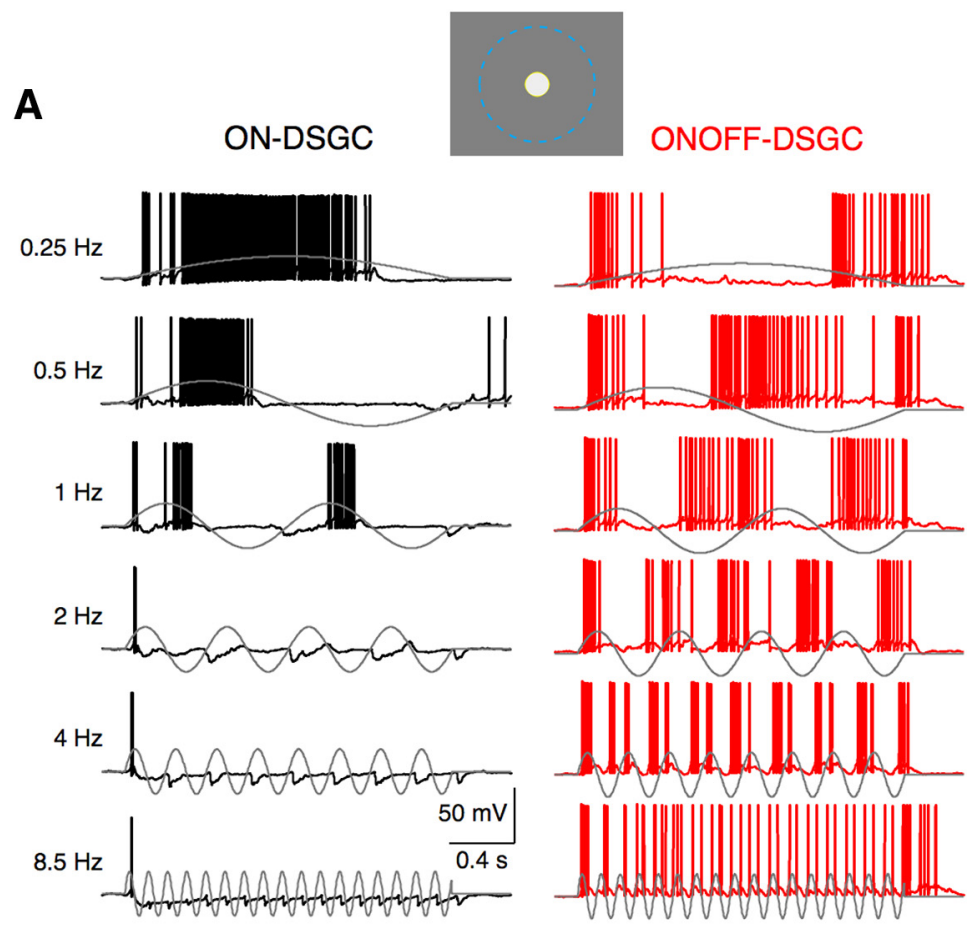

B

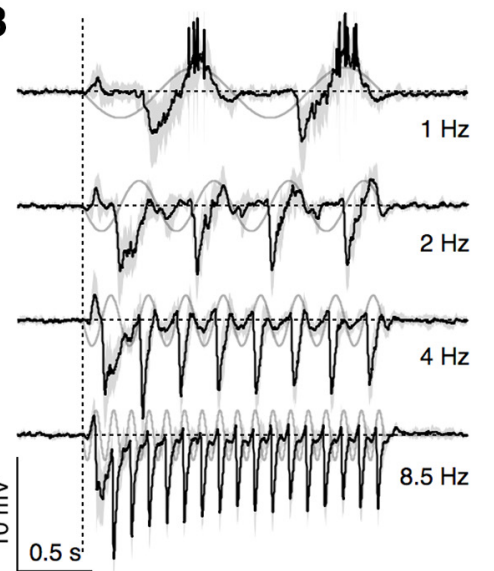

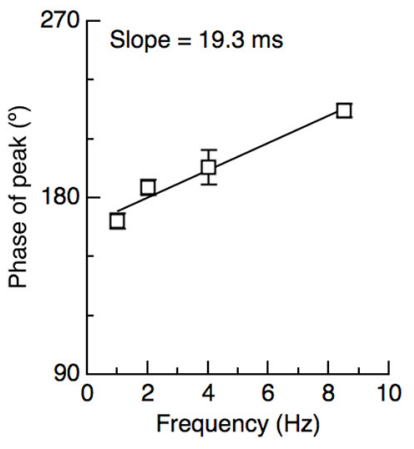

Figure 4. ON-DSGCS but not ONOFF-DSGCs receive a transient inhibitory input that is activated at high flicker frequencies. Responses to a flickering spot centered on the receptive field to illustrate the temporal tuning. $A$, Simultaneous voltage recordings from adjacent $0 \mathrm{~N}$ - and ONOFF-DSGCs with overlapping receptive fields at a range of temporal frequencies. Stimulus timing is shown by the overlying the traces. $\boldsymbol{B}$, Average voltage responses from $10 \mathrm{ON}$-DSGCs during $1,2,4$, and $8.5 \mathrm{~Hz}$ sinusoidal flicker stimulation. Shading shows the SD; stimulus timing is superimposed in gray. C, Phase of the peak IPSP versus stimulus frequency measured from the second stimulus cycle. The solid line shows the linear regression. The slope of the line corresponds to a fixed time delay of $19.3 \mathrm{~ms}$.

ulus cycle. The IPSPs activated sharply at a fixed phase of $155^{\circ}$ (Fig. 4C, intercept of fitted line). The increase in the phase delay with increasing stimulus frequency was consistent with a fixed time-delay of $\sim 19.3 \mathrm{~ms}$ (Fig. $4 C$, slope of fitted line). A second, slow component to the IPSPs was also seen and is particularly evident at 4 and $8.5 \mathrm{~Hz}$ (Fig. $4 \mathrm{~B}$ ) as a slowly decaying hyperpolarization activated at the start of the stimulus. We next made current recordings under voltage-clamp to investigate the synaptic basis of these light-evoked postsynaptic potentials.

We used the same flickering spot stimulus (Fig. 5A1) and recorded light-evoked synaptic currents over a range of holding potentials and calculated the underlying excitatory and inhibitory conductance components (Taylor and Vaney, 2002; Venkat- aramani and Taylor, 2016). Inhibition comprised fast, transient stimulus-locked inputs (Fig. 5A2), which appeared to be superimposed on a slower, sustained component. It seems likely that the slower sustained component includes an inhibitory input activated during the Off-phase of the stimulus, which is clearly evident at the lower stimulus frequencies (Fig. 5A2, arrows), although one cannot rule out contribution from a slower ON inhibitory component with a longer duration. The time course of the sustained envelope is particularly evident at the highest stimulus frequency (Fig. 5A2, $8.5 \mathrm{~Hz}$ trace). It is largest at the start of the stimulus and declines markedly within a few hundred milliseconds. The excitatory conductance was modulated at the stimulus frequency, with a peak of $\sim 4-5 \mathrm{nS}$ that remained constant with increasing stimulus frequency (Fig. 5A3,B, solid symbols). Note that the phasic inhibition turns on more sharply than the excitation (Fig. $5 A$, compare responses at 1 and $2 \mathrm{~Hz}$ ). Overall, these results indicate that the hyperpolarizing PSPs seen in current-clamp are consistent with the presence of direct inhibitory inputs to the ON-DSGCs.

It is well established that DSGCs receive a strong asymmetric GABAergic input that is critical for generating directional responses (Taylor et al., 2000; Vaney et al., 2001; Fried et al., 2002). Previous work has shown that the inhibitory inputs to ONOFF-DSGCs are mediated by GABA receptors (Wyatt and Day, 1976; Caldwell and Daw, 1978; Massey et al., 1997; Fried et al., 2005; Lee et al., 2010). We next tested the hypothesis that the inhibitory inputs seen in the ON-DSGCs were also mediated entirely by GABAergic mechanisms by examining the pharmacological sensitivity of the inhibition. We recorded responses to a centered flickering spot in control and during application of $10 \mu \mathrm{M}$ SR93551 and $50 \mu \mathrm{M}$ TPMPA to block $\mathrm{GABA}_{\mathrm{A}}$ and $\mathrm{GABA}_{\mathrm{C}}$ receptors (GABA block). The flickering spotstimulus was identical to that shown in Figure 5. GABA block appeared to slightly suppress the fast IPSCs, whereas excitation was enhanced relative to control (Fig. 6A, green). The subsequent addition of $1 \mu \mathrm{M}$ strychnine to block glycine receptors completely blocked inhibition but had little additional effect on excitation (Fig. 6A, magenta). Similar experiments were performed in a second group of cells but using a stimulus bar moving at $10 \%$ in the cell's preferred direction to minimize the magnitude of the directional GABAergic input from SBACs. GABA block had little effect on the preferreddirection inhibition, but strongly enhanced the excitatory input, which also became more sustained (Fig. $6 B$, green). Similar to the flickering spot, blocking both GABA and glycine receptors completely suppressed the inhibitory input (Fig. 6, magenta). These 
A1

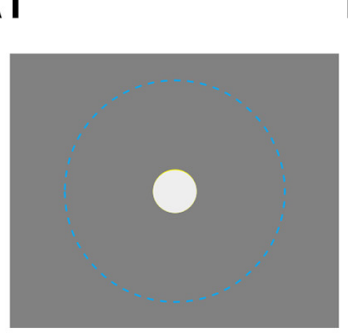

A2 Inhibition
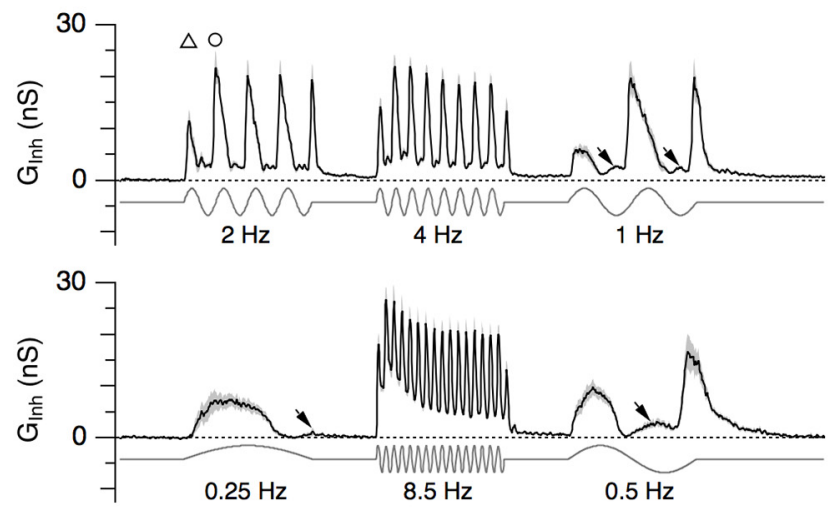

A3Excitation
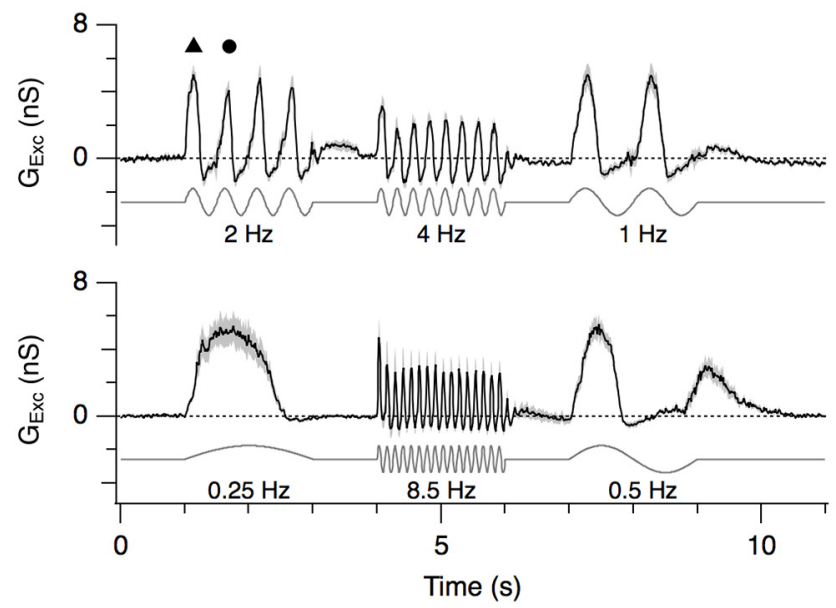

Figure 5. A rapid transient inhibitory synaptic conductance is observed ON-DSGCS. A1, The stimulus was a sinusoidally-modulated $300 \mu \mathrm{m}$ diameter spot, $80 \%$ contrast centered on the receptive field. $\mathbf{A 2}, \mathbf{A 3}$, Net light-evoked inhibitory and excitatory synaptic conductances activated by a range of flicker frequencies (for details of analysis, see Materials and Methods). Within each trial the spot was flickered at three frequencies, as indicated by the stimulus timing beneath each trace. Shading shows the SEM (top, $n=9$ cells; bottom, $n=6$ cells). The arrows highlight the inhibition activated during the OFF-phase of the stimulus. The symbols above the $2 \mathrm{~Hz}$ responses illustrate the measurement points for $\boldsymbol{B}$. The triangles represent the peak amplitude during the first halfstimulus cycle, and the circles show the amplitude during the second cycle. $\boldsymbol{B}$, Peak amplitude of the inhibitory and excitatory conductances at the stimulus-cycle time-points indicated in $\mathbf{A} \mathbf{2}$ and $\boldsymbol{A} \mathbf{3}$.

results indicate that ON-DSGCs receive a strong direct glycinergic inhibitory input. The effects of the inhibitory blockers on excitation were complex; blocking GABA-receptors alone prolonged the time course of the excitation, whereas the addition of the glycinergic blocker produced excitation very similar to control.

These results suggest that glycinergic inhibition specific to ON-DSGCs largely determines the different temporal tuning of the two types of DSGCs, and most importantly, the different sensitivity to saccadic motion. This hypothesis predicts that blocking glycine receptors should allow ON-DSGCs to become more responsive at high temporal frequencies. Confirming this prediction, ON-DSGCs responded strongly to flickering stimuli at 2 and $8.5 \mathrm{~Hz}$ after glycinergic inhibition as blocked (Fig. 7A). These changes in excitability were paralleled by changes in the synaptic conductances. Inhibition was strongly suppressed during glycinergic block (Fig. $7 B$, averages of 4 cells). The sustained envelope disappeared, consistent with this component also relying on glycinergic receptors. The residual IPSCs in Figure $7 B$ presumably reflect GABAergic input, largely from starburst amacrine cells. As predicted, the suppression of spiking observed during saccadic global motion of natural scenes was lost in the presence of the glycinergic blocker (Fig. 7C). The number of spikes recorded during preferred and null direction saccades increased significantly (paired $t$ test, preferred: $p=2.4 \times 10^{-3}$, null: $p=9.9 \times 10^{-5}$ ). Note that with glycine receptors blocked, the ON-DSGCs responded in the preferred and null directions indicating that directional tuning was weaker at these high velocities (Fig. 7C, blue and green arrows), as was observed for the ONOFF-DSGCs (Fig. 1B). Finally, we tested the effects of strychnine on the speed tuning for local motion. After blocking glycinergic inputs, there was little effect on the ON-responses of the ONOFF-DSGCs (Fig. 7D, top), but a large potentiation of the ON-DSGC response (Fig. 7D, bottom), at least at high velocities. DSGCs receive excitatory input partially through cholinergic inputs (Ariel and Daw, 1982; Kittila and Massey, 1997), which can be suppressed by micromolar concentrations of strychnine (Renna et al., 2007). The major effect of strychnine in our experiments was consistent with suppression of glycine receptors, because excitatory drive was generally increased. Perhaps the slightly lower firing rate in response to slow drift of the visual scene could be attributable to cholinergic blockade (Fig. 7C), but further work would be required to test that hypothesis. Overall, after scaling for absolute spike rate, the responses for the two cell types became comparable in the presence of strychnine, and therefore the speed tuning became essentially indistinguishable (Fig. 7E).

\section{Discussion}

The results demonstrate that glycinergic inhibitory inputs specific to ON- but not ONOFF-DSGCs, are responsible for differences in the temporal response properties between the two classes of DSGCs. The inhibition is activated by both local and global visual stimuli and serves to suppress spike output from the ONDSGCs during fast image motion (Figs. 1, 3). Unlike the directional GABAergic input to these cells, the glycinergic inhibition is activated regardless of the direction of image motion. Thus, at least two inhibitory mechanisms function independently within the dendrites of ON-DSGCs, a GABAergic component that produces directional responses, and glycinergic components that mediate saccadic suppression and tune the cells to respond best to relatively low speeds. During simulated saccades, ONOFFDSGCs respond regardless of the direction of image motion, indicating that the directional GABAergic inputs were ineffective at high velocities (Fig. 1, red). The ON-DSGCs showed similar behavior when glycinergic inputs were blocked (Fig. 7C). Such high velocities may be functionally similar to static flashes, which cause DSGCs to spike because the GABAergic inhibition from starburst amacrine cells arrives slightly delayed relative to the excitation (Sivyer et al., 2010). The ability of the glycinergic circuit to suppress spiking for rapid contrast changes appears similar to the role of glycinergic receptors in temporal tuning of 


\section{A Flickering spot $300 \mu \mathrm{m}$}
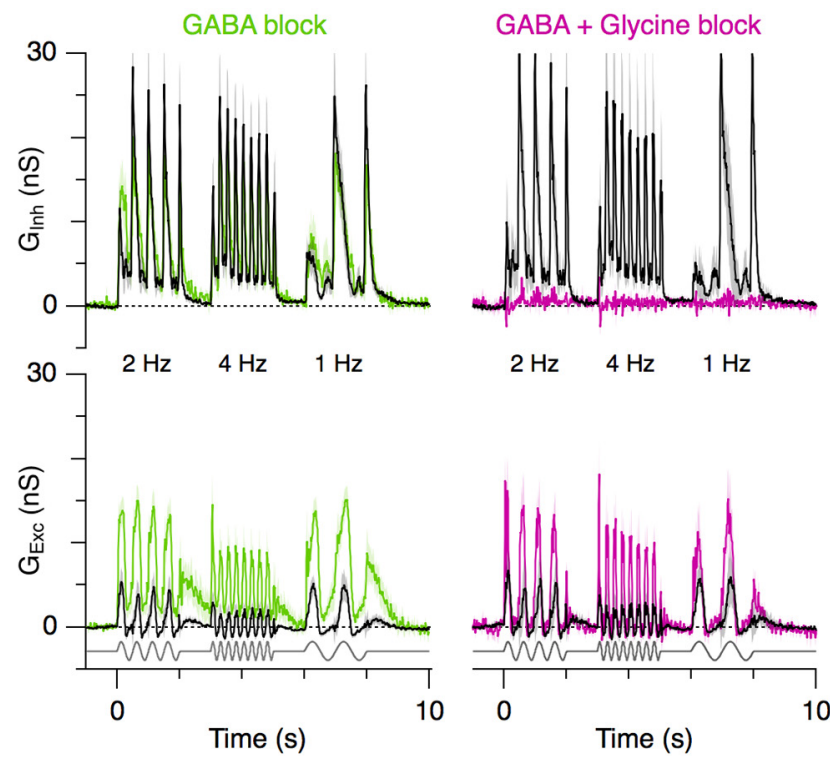

B Moving bar $0.3 \times 5 \mathrm{~mm}$
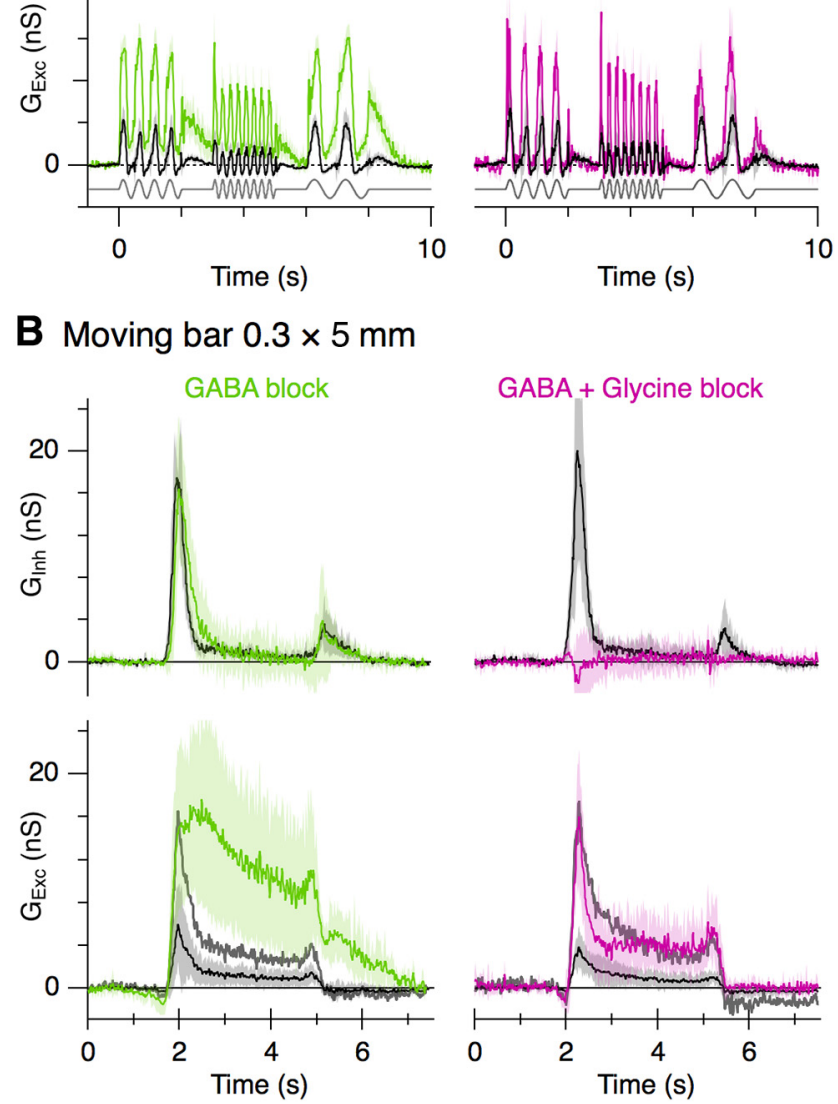

10 major role for ONOFF-DSGCs in generating OKN, because these cells still produce strong directional responses through the OFFpathway when the ON-pathway is suppressed (Kittila and Massey, 1995). OFF ganglion cells are incapable of driving the optokinetic reflex in zebrafish (Emran et al., 2007).

Our current findings seem consistent with the idea that ONDSGCs alone are critical for generating the OKN. The ON-DSGCs could correct for small, slow drift of the image on the retina, which might occur during steady gaze, by activating high-gain feedback pathways producing compensatory eye movements that stabilize the retinal image. Conversely, sudden or continuous motion producing strong optical flow across the retina will activate the glycinergic inputs and silence output from the ONDSGCs, thus preventing inappropriate activation of the highgain compensatory eye movements. ONOFF-DSGCs on the other hand, appear to well suited to signal saccade onset, or global optical flow (Sabbah et al., 2017). They modulate their firing continuously as a function of the speed (Fig. 7E), allowing them to signal changes in image motion on the retina. Moreover, a given image pattern passing across an ONOFF-DSGC receptive field appears to produce a fairly constant number of spikes over a range of velocities (Fig. 3D), suggesting that these cells may be good substrates for signaling the amount of optical flow. On the other hand, ONOFF-DSGCs are suppressed by wide-field stimuli in mouse and rabbit (Chiao and Masland, 2003; Olveczky et al., 2003; Hoggarth et al., 2015; Im and Fried, 2016), which would tend to reduce ability to signal optical flow. Nonetheless, the central projection patterns of ON- and ONOFF-DSGCs in mouse (Dhande et al., 2013; Gauvain and Murphy, 2015), seem to be broadly similar to rabbit consistent with conservation of the fundamental directional circuitry in these two species.

A previous analysis performed in head-fixed animals (Collewijn, 1969), concluded that the open loop gain of OKN in rabbits declines at frequencies $>\sim 1 \%$, and that the closed loop gain is lower than might be expected for the open-loop results (Collewijn, 1969). The suggestion was that "saccadic interruptions in visual input" might explain these findings. Indeed, during OKN experiments, rapid "stepwise" movement of the visual scene to a different location failed to drive compensatory eye movements (Collewijn, 1981). Moreover, higher closed-loop gain was found for sine-wave modulated motion, where saccades were relatively local-edge-detector ganglion cells (Venkataramani et al., 2014). The primary role for glycinergic circuits in shaping temporal tuning at high velocities is further evident in the similar speed tuning for ON- and ONOFF-DSGCs, seen when glycinergic transmission was blocked. At low velocities and stimulus frequencies, where spiking is more sustained, the properties of the excitatory inputs also appear to contribute to temporal tuning (Figs. $3 A$,
$4 A$ ), because the sustained spiking likely reflects the more sus-
tained excitatory inputs to ON-DSGCs relative to ONOFFDSGCs (Sivyer et al., 2010). It is not known whether this
excitatory difference results from different presynaptic bipolar cells or synaptic heterogeneity within a common type. Overall, the markedly different responses of ON-DSGCs and ONOFF-DSGCs during rapid visual motion appear attributable largely to a glycinergic input
that targets ON-DSGCs but not ONOFF-DSGCs.
The different functional properties for the two types of DSGCs seem to be attuned to their distinct central projections. ONOFF-
DSGCs project to the LGN and are thus likely involved in imageforming and perceptual vision. ON-DSGCs are conspicuous
among ganglion cells by their primary projection to the accessory optic system (AOS; Collewijn, 1975; Oyster et al., 1980; Ellis et al., 2016; Martersteck et al., 2017), where their afferent signals drive
the optokinetic reflex (OKR) that helps stabilize the image on the retina (Erickson and Barmack, 1980). Some ONOFF-DSGCs in
mouse also project to the AOS in addition to their primary projections to the superior colliculus and LGN (Kay et al., 2011; Dhande et al., 2013). However, the optokinetic nystagmus erage 6. Inibitory synaptic inputs to ON-DSGCs comprise direct glycinergic inputs. of $10 \mu \mathrm{m}$ SR95531 + $10 \mu \mathrm{m}$ TPMPA (GABA block, green; $n=5$ ). Top row shows inhibitio remained stable enough for the subsequent addition of $1 \mu \mathrm{m}$ strychnine (GABA + Glycine block, magenta; $n=3$ ). (entered light spot, $300 \mu \mathrm{m}$ diameter, $80 \%$ contrast. $\boldsymbol{B}$, Average $\mu \mathrm{m} / \mathrm{s}, 80 \%$ contrast) moving through the center of the receptive field in the preferred motion. Traces show control (black), GABAergic block (green; $n=5$ ), and subsequent GABAergic and lines show the control traces scaled to match the maximum amplitude during drug application to compare the time course of the excitation during inhibitory block. 
rare (Collewijn, 1969). Our results showing strong suppression of spiking during rapid saccades directly demonstrate saccadic interruption of retinal output, at least that arising from the ON-DSGCs. The higher spike output from ONOFFDSGCs during saccades suggest that if these cells make a convergent contribution to the central OKN circuits in the rabbit, they likely play different roles. For example, in the wallaby, recordings from the nucleus of the optic tract and dorsal terminal nucleus revealed two types of direction-selective units, slow and fast (Ibbotson et al., 1994). The slow units were inhibited by saccades in either direction, similar to the ON-DSGCs illustrated here.

\section{Glycinergic inhibition and temporal tuning}

The results demonstrate a key role for inhibitory inputs in generating saccadic suppression of the ON-DSGCs. The flicker stimuli reveal two characteristic temporal components to the inhibition (Figs. 4, 5); a rapid phasic component that modulates at the stimulus frequency, and a slower component that generates a sustained envelope that peaks within a few tens of milliseconds and decays over a few hundred milliseconds (Figs. 4B, 5, 6A). The increasing phase-delay observed with increasing frequency (Fig. 4C), suggests a fixed time delay for synaptic transmission. The inferred delay, close to $20 \mathrm{~ms}$, is consistent with many previous estimates of synaptic delays for surround-inhibition in the retina (Gouras and Zrenner, 1979; EnrothCugell et al., 1983; Benardete and Kaplan, 1997; Molnar and Werblin, 2007; Cui et al., 2016; Murphy-Baum and Taylor, 2018). However, previous studies estimated inhibitory delays relative to excitation, while the current results require that inhibition and excitation be coincident, and therefore exhibit similar synaptic delays. A previous analysis of temporal tuning in local-edge-detector ganglion cells point to a similar role for glycinergic transmission, and also predicts that inhibition and excitation should be coincident (Venkataramani et al., 2014). The circuit mechanisms that ensure that inhibition and excitation are either temporally coincident or delayed are not well understood.

The slow component of the glycinergic inhibition, which may result from temporal summation of relatively sustained inhibition arising from the both the ONand OFF-pathways, is likely glycinergic because it is suppressed by strychnine

\section{A ONDSGC Control Strychnine}
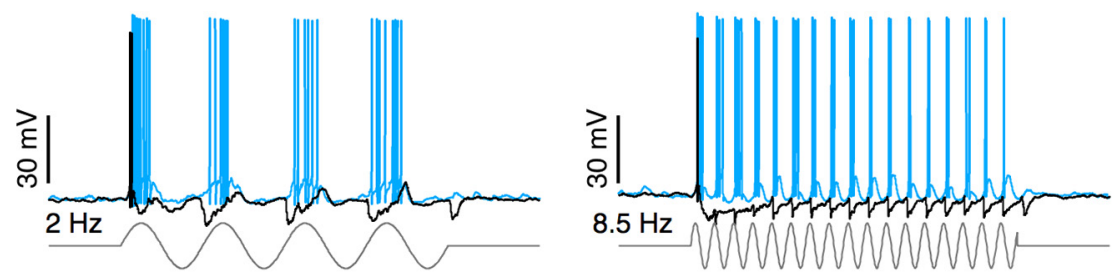

\section{B ON DSGC}
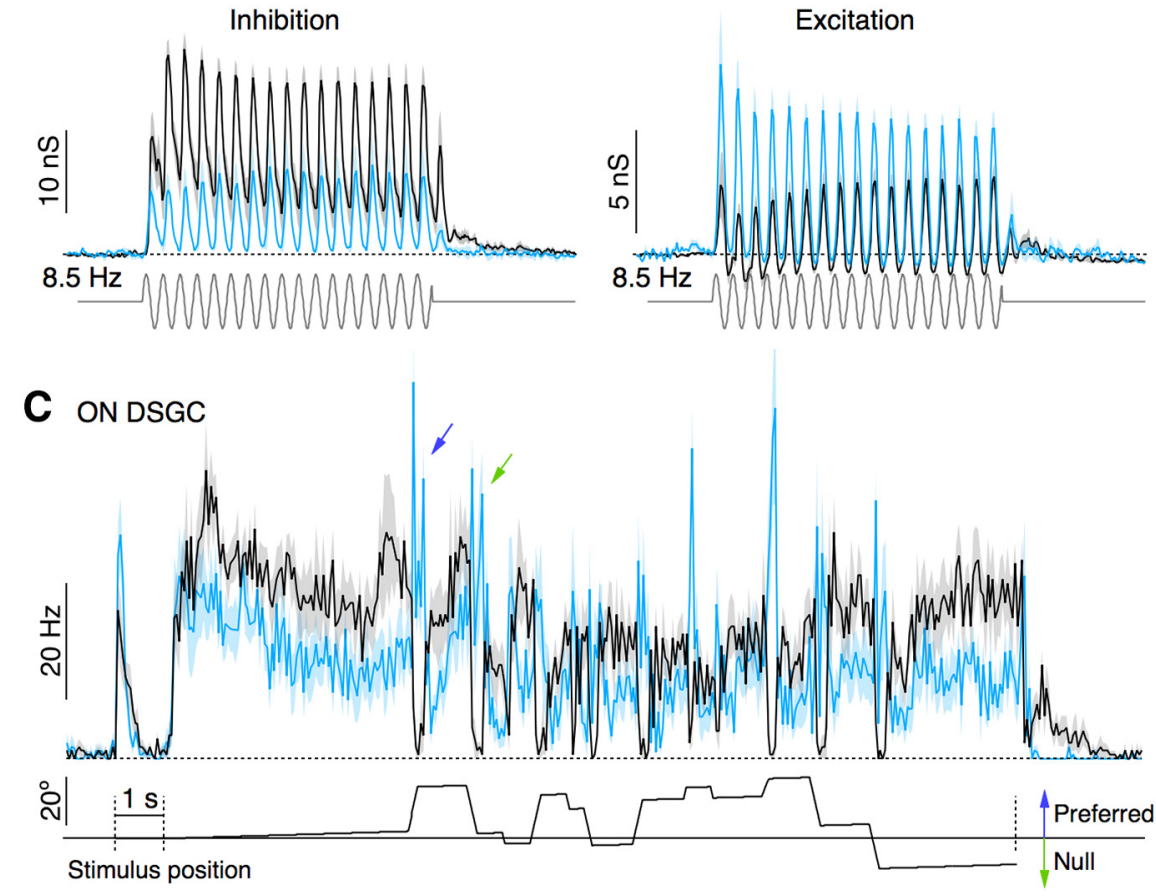

D ONOFF DSGC

E
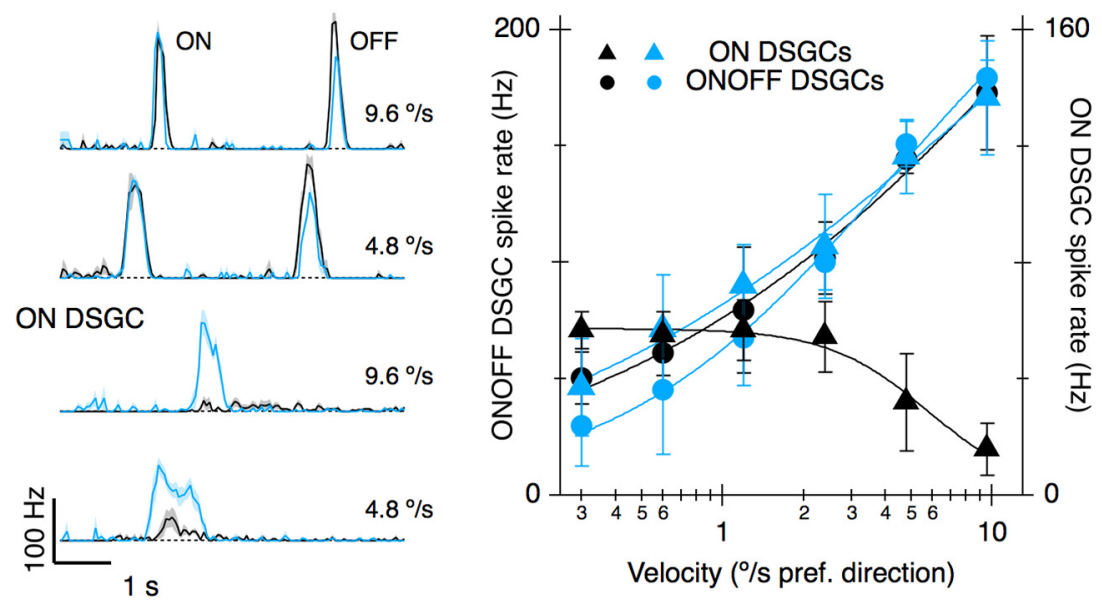

Figure 7. Speed-tuning in $0 \mathrm{~N}$ - and 0 NOFF-DSGCs is similar after glycinergic block. $\boldsymbol{A}$, Representative voltage responses during center flicker (diameter, $300 \mu \mathrm{m}$; contrast, 80\%) at two frequencies as indicated in control (black; replotted from Fig. 4A) and in the presence of $1 \mu \mathrm{m}$ strychnine (blue). $\boldsymbol{B}$, Average synaptic conductances $(n=4)$ activated by a centered stimulus spot (diameter, $300 \mu \mathrm{m}$; contrast, $80 \%$ ) modulated at $8.5 \mathrm{~Hz}$, in control (black) and in the presence of $1 \mu \mathrm{m}$ strychnine (blue). C, PSTHs in response to global drift of a random checkerboard stimulus similar to that shown in Figure 1. Average of six ON-DSGCs in control and during glycinergic block. The arrows highlight preferred and null direction saccades. Spiking increases in both cases. D, PSTHs averaged from four ONOFF-DSGCs and seven ON-DSGCs before (black) and during application of strychnine (blue). Shading shows SEM. Light stimulus was a $300 \mu \mathrm{m}$ wide bar (same stimulus as Fig. $3 B$ ) drifting in the preferred direction at various velocities. Speed of the stimulus indicated next to the traces. $\boldsymbol{E}$, Peak spike rates shown for the full range of stimulus velocities. Circles show the $0 \mathrm{~N}$ response of the ONOFF-DSGCs. The scaling of the $y$-axes is set to normalize the amplitude. 
(Fig. $7 B$ ). The slow component represents a considerable fraction of the total inhibition, and could produce sustained hyperpolarization of the ON-DSGCs during saccadic eye movements in the rabbit, which can be up to $\sim 250 \mathrm{~ms}$ (Collewijn, 1977). The faster transient component may be important for countermanding rapidly fluctuating excitatory inputs activated by a rapidly moving image. A further factor driving temporal tuning in the ONDSGCs is the excitatory-inhibitory synaptic conductance ratio, which decreased with stimulus frequency because of increased inhibition (Fig. $5 B$ ). It is also noteworthy, that the inhibition shutsoff rapidly (Fig. 5A2, 4 and $8 \mathrm{~Hz}$ ), which would allow the ONDSGCs to recover rapidly from the saccadic-suppression (Fig. $1 B)$. Thus, at the end of a saccade, the ON-DSGC will quickly resume encoding slow image-slip on retina and thus re-establish the signals required for image stabilization.

These results do not preclude the possibility that differences in GABAergic transmission also make some contribution to the temporal tuning of the two DSGC types. Understanding the functional roles of glycinergic and GABAergic inhibitory systems in the retina remains an ongoing challenge (Masland, 2012). Feedforward inhibition is known to convey specific computational features to several ganglion cells types including direction-selective (Vaney et al., 2012), orientation-selective (Nath and Schwartz, 2016; Venkataramani and Taylor, 2016), suppressed-by-contrast (Sivyer et al., 2011; Jacoby et al., 2015; Tien et al., 2016), and looming-sensitive cells (Münch et al., 2009). Our results further illustrate how targeted feedforward inhibition can bestow a computational property onto a specific ganglion cell type. A question for future research is whether the glycinergic amacrine cells involved are unique to this ON-DS circuit, or whether they produce similar saccadic suppression in other ganglion cell types.

\section{References}

Ackert JM, Farajian R, Völgyi B, Bloomfield SA (2009) GABA blockade unmasks an OFF response in ON direction selective ganglion cells in the mammalian retina. J Physiol 587:4481-4495.

Amthor FR, Keyser KT, Dmitrieva NA (2002) Effects of the destruction of starburst-cholinergic amacrine cells by the toxin AF64A on rabbit retinal directional selectivity. Vis Neurosci 19:495-509.

Angelaki DE, Cullen KE (2008) Vestibular system: the many facets of a multimodal sense. Annu Rev Neurosci 31:125-150.

Ariel M, Daw NW (1982) Pharmacological analysis of directionally sensitive rabbit retinal ganglion cells. J Physiol 324:161-185.

Barlow HB, Hill RM (1963) Selective sensitivity to direction of movement in ganglion cells of the rabbit retina. Science 139:412-414.

Barlow HB, Hill RM, Levick WR (1964) Retinal ganglion cells responding selectively to direction and speed of image motion in the rabbit. J Physiol 173:377-407.

Benardete EA, Kaplan E (1997) The receptive field of the primate P retinal ganglion cell. I: Linear dynamics. Vis Neurosci 14:169-185.

Borg-Graham LJ (2001) The computation of directional selectivity in the retina occurs presynaptic to the ganglion cell. Nat Neurosci 4:176-183.

Briggman KL, Helmstaedter M, Denk W (2011) Wiring specificity in the direction-selectivity circuit of the retina. Nature 471:183-188.

Caldwell JH, Daw NW (1978) Effects of picrotoxin and strychnine on rabbit retinal ganglion cells: changes in centre surround receptive fields. J Physiol 276:299-310.

Caldwell JH, Daw NW, Wyatt HJ (1978) Effects of picrotoxin and strychnine on rabbit retinal ganglion cells: lateral interactions for cells with more complex receptive fields. J Physiol 276:277-298.

Chiao CC, Masland RH (2003) Contextual tuning of direction-selective retinal ganglion cells. Nat Neurosci 6:1251-1252.

Collewijn H (1969) Optokinetic eye movements in the rabbit: input-output relations. Vision Res 9:117-132.

Collewijn H (1975) Direction-selective units in the rabbit's nucleus of the optic tract. Brain Res 100:489-508.

Collewijn H (1977) Eye- and head movements in freely moving rabbits. J Physiol 266:471-498.
Collewijn J (1981) The oculomotor system of the rabbit and its plasticity, pp 49-74. Berlin; Heidelberg: Springer

Cruz-Martín A, El-Danaf RN, Osakada F, Sriram B, Dhande OS, Nguyen PL, Callaway EM, Ghosh A, Huberman AD (2014) A dedicated circuit links direction-selective retinal ganglion cells to the primary visual cortex. Nature 507:358-361.

Cui Y, Wang YV, Park SJ, Demb JB, Butts DA (2016) Divisive suppression explains high-precision firing and contrast adaptation in retinal ganglion cells. eLife 5:e19460.

Dhande OS, Estevez ME, Quattrochi LE, El-Danaf RN, Nguyen PL, Berson DM, Huberman AD (2013) Genetic dissection of retinal inputs to brainstem nuclei controlling image stabilization. J Neurosci 33:17797-17813.

Ellis EM, Gauvain G, Sivyer B, Murphy GJ (2016) Shared and distinct retinal input to the mouse superior colliculus and dorsal lateral geniculate nucleus. J Neurophysiol 116:602-610.

Emran F, Rihel J, Adolph AR, Wong KY, Kraves S, Dowling JE (2007) OFF ganglion cells cannot drive the optokinetic reflex in zebrafish. Proc Natl Acad Sci U S A 104:19126-19131.

Enroth-Cugell C, Robson JG, Schweitzer-Tong DE, Watson AB (1983) Spatio-temporal interactions in cat retinal ganglion cells showing linear spatial summation. J Physiol 341:279-307.

Erickson RG, Barmack NH (1980) A comparison of the horizontal and vertical optokinetic reflexes of the rabbit. Exp Brain Res 40:448-456.

Euler T, Detwiler PB, Denk W (2002) Directionally selective calcium signals in dendrites of starburst amacrine cells. Nature 418:845-852.

Fried SI, Münch TA, Werblin FS (2002) Mechanisms and circuitry underlying directional selectivity in the retina. Nature 420:411-414.

Fried SI, Münch TA, Werblin FS (2005) Directional selectivity is formed at multiple levels by laterally offset inhibition in the rabbit retina. Neuron $46: 117-127$

Gauvain G, Murphy GJ (2015) Projection-specific characteristics of retinal input to the brain. J Neurosci 35:6575-6583.

Gouras P, Zrenner E (1979) Enhancement of luminance flicker by coloropponent mechanisms. Science 205:587-589.

Hoggarth A, McLaughlin AJ, Ronellenfitch K, Trenholm S, Vasandani R, Sethuramanujam S, Schwab D, Briggman KL, Awatramani GB (2015) Specific wiring of distinct amacrine cells in the directionally selective retinal circuit permits independent coding of direction and size. Neuron $86: 276-291$.

Huberman AD, Wei W, Elstrott J, Stafford BK, Feller MB, Barres BA (2009) Genetic identification of an on-off direction-selective retinal ganglion cell subtype reveals a layer-specific subcortical map of posterior motion. Neuron 62:327-334.

Hughes A, Vaney DI (1981) Contact lenses change the projection of visual field onto rabbit peripheral retina. Vision Res 21:955-956.

Ibbotson MR, Mark RF, Maddess TL (1994) Spatiotemporal response properties of direction-selective neurons in the nucleus of the optic tract and dorsal terminal nucleus of the wallaby, Macropus engenii. J Neurophysiol 72:2927-2943.

Im M, Fried SI (2016) Directionally selective retinal ganglion cells suppress luminance responses during natural viewing. Sci Rep 6:35708.

Iwakabe H, Katsuura G, Ishibashi C, Nakanishi S (1997) Impairment of pupillary responses and optokinetic nystagmus in the mGluR6-deficient mouse. Neuropharmacology 36:135-143.

Jacoby J, Zhu Y, DeVries SH, Schwartz GW (2015) An amacrine cell circuit for signaling steady illumination in the retina. Cell Rep 13:2663-2670.

Kay JN, De la Huerta I, Kim IJ, Zhang Y, Yamagata M, Chu MW, Meister M, Sanes JR (2011) Retinal ganglion cells with distinct directional preferences differ in molecular identity, structure, and central projections. J Neurosci 31:7753-7762.

Kittila CA, Massey SC (1995) Effect of ON pathway blockade on directional selectivity in the rabbit retina. J Neurophysiol 73:703-712.

Kittila CA, Massey SC (1997) Pharmacology of directionally selective ganglion cells in the rabbit retina. J Neurophysiol 77:675-689.

Knapp AG, Ariel M, Robinson FR (1988) Analysis of vertebrate eye movements following intravitreal drug injections: I. Blockade of retinal ONcells by 2-amino-4-phosphonobutyrate eliminates optokinetic nystagmus. J Neurophysiol 60:1010-1021.

Lee S, Zhou ZJ (2006) The synaptic mechanism of direction selectivity in distal processes of starburst amacrine cells. Neuron 51:787-799.

Lee S, Kim K, Zhou ZJ (2010) Role of ACh-GABA cotransmission in detecting image motion and motion direction. Neuron 68:1159-1172. 
Lettvin JY, Maturana HR, McCulloch WS, Pitts WH (1959) What the frog's eye tells the frog's brain. Proc IRE 47:1940-1951.

Martersteck EM, Hirokawa KE, Zeng H, Sanes JR, Harris JA, Evarts M, Bernard A, Duan X, Li Y, Ng L, Oh SW, Ouellette B, Royall JJ, Stoecklin M, Wang Q, Sanes JR, Harris JA (2017) Diverse central projection patterns of retinal ganglion cells. Cell Rep 18:2058-2072.

Masland RH (2012) The neuronal organization of the retina. Neuron $76: 266-280$

Massey SC, Linn DM, Kittila CA, Mirza W (1997) Contributions of GABAA receptors and GABAC receptors to acetylcholine release and directional selectivity in the rabbit retina. Vis Neurosci 14:939-948.

Molnar A, Werblin F (2007) Inhibitory feedback shapes bipolar cell responses in the rabbit retina. J Neurophysiol 98:3423-3435.

Münch TA, da Silveira RA, Siegert S, Viney TJ, Awatramani GB, Roska B (2009) Approach sensitivity in the retina processed by a multifunctional neural circuit. Nat Neurosci 12:1308-1316.

Murphy-Baum BL, Taylor WR (2018) Diverse inhibitory and excitatory mechanisms shape temporal tuning in transient OFF $\alpha$ ganglion cells in the rabbit retina. J Physiol 596:477-495.

Nath A, Schwartz GW (2016) Cardinal orientation selectivity is represented by two distinct ganglion cell types in mouse retina. J Neurosci 36:3208-3221.

Nirenberg S, Meister M (1997) The light response of retinal ganglion cells is truncated by a displaced amacrine circuit. Neuron 18:637-650.

Olveczky BP, Baccus SA, Meister M (2003) Segregation of object and background motion in the retina. Nature 423:401-408.

Oyster CW (1968) The analysis of image motion by the rabbit retina. J Physiol 199:613-635.

Oyster CW, Barlow HB (1967) Direction-selective units in rabbit retina: distribution of preferred directions. Science 155:841-842.

Oyster CW, Takahashi E, Collewijn H (1972) Direction-selective retinal ganglion cells and control of optokinetic nystagmus in the rabbit. Vis Res 12:183-193.

Oyster CW, Simpson JI, Takahashi ES, Soodak RE (1980) Retinal ganglion cells projecting to the rabbit accessory optic system. J Comp Neurol 190:49-61.

Peirce JW (2007) PsychoPy: psychophysics software in python. J Neurosci Methods 162:8-13.

Renna JM, Strang CE, Amthor FR, Keyser KT (2007) Strychnine, but not PMBA, inhibits neuronal nicotinic acetylcholine receptors expressed by rabbit retinal ganglion cells. Vis Neurosci 24:503-511.

Rentería RC, Tian N, Cang J, Nakanishi S, Stryker MP, Copenhagen DR (2006) Intrinsic ON responses of the retinal OFF pathway are suppressed by the ON pathway. J Neurosci 26:11857-11869.

Roska B, Werblin F (2001) Vertical interactions across ten parallel, stacked representations in the mammalian retina. Nature 410:583-587.

Sabbah S, Gemmer JA, Bhatia-Lin A, Manoff G, Castro G, Siegel JK, Jeffery N, Berson DM (2017) A retinal code for motion along the gravitational and body axes. Nature 546:492-497.

Semm P (1978) Antidromically activated direction selective ganglion cells of the rabbit. Neurosci Lett 9:207-211.

Simoncelli EP, Olshausen BA (2001) Natural image statistics and neural representation. Annu Rev Neurosci 24:1193-1216.

Simpson JI (1984) The accessory optic system. Annu Rev Neurosci 7:13-41.

Sivyer B, Williams SR (2013) Direction selectivity is computed by active dendritic integration in retinal ganglion cells. Nat Neurosci 16:1848-1856.
Sivyer B, van Wyk M, Vaney DI, Taylor WR (2010) Synaptic inputs and timing underlying the velocity tuning of direction-selective ganglion cells in rabbit retina. J Physiol 588:3243-3253.

Sivyer B, Venkataramani S, Taylor WR, Vaney DI (2011) A novel type of complex ganglion cell in rabbit retina. J Comp Neurol 519:3128-3138.

Soodak RE, Simpson JI (1988) The accessory optic system of rabbit: I. Basic visual response properties. J Neurophysiol 60:2037-2054.

Sun W, Deng Q, Levick WR, He S (2006) ON direction-selective ganglion cells in the mouse retina. J Physiol 576:197-202.

Taylor WR, Vaney DI (2002) Diverse synaptic mechanisms generate direction selectivity in the rabbit retina. J Neurosci 22:7712-7720.

Taylor WR, He S, Levick WR, Vaney DI (2000) Dendritic computation of direction selectivity by retinal ganglion cells. Science 289:2347-2350.

Tien NW, Kim T, Kerschensteiner D (2016) Target-specific glycinergic transmission from VGluT3-expressing amacrine cells shapes suppressive contrast responses in the retina. Cell Rep 15:1369-1375.

van Hateren JH, van der Schaaf A (1998) Independent component filters of natural images compared with simple cells in primary visual cortex. Proc Biol Sci 265:359-366.

van Wyk M, Taylor WR, Vaney DI (2006) Local edge detectors: a substrate for fine spatial vision at low temporal frequencies in rabbit retina. J Neurosci 26:13250-13263.

Vaney DI, He S, Taylor WR, Levick WRL (2001) Direction-selective ganglion cells in the retina. In: Motion vision. computational, neural and ecological constraints (Zanker JM, Zeil J, eds), pp 13-56. Berlin: Springer.

Vaney DI, Sivyer B, Taylor WR (2012) Direction selectivity in the retina: symmetry and asymmetry in structure and function. Nat Rev Neurosci 13:194-208.

Venkataramani S, Taylor WR (2010) Orientation selectivity in rabbit retinal ganglion cells is mediated by presynaptic inhibition. J Neurosci 30:15664-15676.

Venkataramani S, Taylor WR (2016) Synaptic mechanisms generating orientation selectivity in the ON pathway of the rabbit retina. J Neurosci 36:3336-3349.

Venkataramani S, Van Wyk M, Buldyrev I, Sivyer B, Vaney DI, Taylor WR (2014) Distinct roles for inhibition in spatial and temporal tuning of local edge detectors in the rabbit retina. PLoS One 9:e88560.

Wallace DJ, Greenberg DS, Sawinski J, Rulla S, Notaro G, Kerr JN (2013) Rats maintain an overhead binocular field at the expense of constant fusion. Nature 498:65-69.

Wei W, Hamby AM, Zhou K, Feller MB (2011) Development of asymmetric inhibition underlying direction selectivity in the retina. Nature 469:402-406.

Wyatt HJ, Daw NW (1975) Directionally sensitive ganglion cells in the rabbit retina: specificity for stimulus direction, size, and speed. J Neurophysiol 38:613-626.

Wyatt HJ, Day NW (1976) Specific effects of neurotransmitter antagonists on ganglion cells in rabbit retina. Science 191:204-205.

Yilmaz M, Meister M (2013) Rapid innate defensive responses of mice to looming visual stimuli. Curr Biol 23:2011-2015.

Yonehara K, Balint K, Noda M, Nagel G, Bamberg E, Roska B (2011) Spatially asymmetric reorganization of inhibition establishes a motion-sensitive circuit. Nature 469:407-410.

Yoshida K, Watanabe D, Ishikane H, Tachibana M, Pastan I, Nakanishi S (2001) A key role of starburst amacrine cells in originating retinal directional selectivity and optokinetic eye movement. Neuron 30:771-780. 